\title{
Research on the application of epoxy surface in the pavement maintenance of the Yilaga Tunnel in Guizhou Province
}

\author{
Miaomiao $\operatorname{Tian}^{1}$, Xiangyan $\mathrm{Wu}^{2,}{ }^{*}$, Xiangling $\mathrm{Chen}^{2}$, Xingbing Xiong ${ }^{3}$, and Jianping Yang ${ }^{2}$ \\ ${ }^{1}$ China Academy of Transportation Sciences, Beijing, China \\ ${ }^{2}$ Chongqing Chengbang Pavement Material Co., Ltd, Chongqing, China \\ ${ }^{3}$ Guizhou Expressway Group Co., Ltd, China
}

\begin{abstract}
There are high mountains and steep roads in Guizhou Province. Affected by the relatively closed environment, high humidity and other factors, the skid resistance and durability of the highway in tunnels were obviously reduced, which affects the normal operation of the asphalt pavement. Based on the pavement maintenance project of the highway in the Yilaga Tunnel in Guizhou Province, a new kind of epoxy surface treatment maintenance technology for asphalt pavement has been introduced in this paper. Through the comparative analysis of friction coefficient, structural depth and other anti-sliding performance before and after construction, the results has shown that the technology can effectively solve the early diseases and significantly improve the anti-sliding performance of the pavement, and assist to reduce the occurrence of traffic accidents.
\end{abstract}

Keywords: Epoxy surface treatment technology; Tunnel asphalt pavement maintenance.

\section{Introduction}

Guizhou Province is located in the south of China, with a lot of mountains and high rainfall environment. The highway tunnel is in a relatively closed special environment, and the high humidity of the pavement has a bad impact on its skid resistance and durability. Under the long-term effect of vehicle load and natural factors, asphalt pavement is prone to early disease, which affects the comfort and safety of road driving. Based on Guizhou Province Science and technology project 'Research on Anti-sliding Treatment Technology of Epoxy Surface of Expressway Asphalt Pavement'(Project number: 2020-123-012), the asphalt pavement epoxy surface treatment maintenance technology is used in the Guizhou Yilaga Tunnel to repair the early diseases of the tunnel pavement, and the friction coefficient, structural depth, bonding strength and other indicators of different time periods before and after construction were compared and analyzed.

\footnotetext{
*Corresponding author: xywucb@qq.com
} 


\section{Engineering application}

Yilaga Tunnel is located on S77 Weiban Expressway in Guizhou Province, it is $2.52 \mathrm{~km}$ long and $21.5 \mathrm{~m}$ wide. The pavement in the tunnel was constructed as the standard of expressways, with a design speed of $80 \mathrm{~km} / \mathrm{h}$. According to the road condition investigation and detection analysis of the tunnel, it has been found that the overall technical condition of the pavement was acceptable and there was no structural damage. The typical diseases were mainly transverse cracks, longitudinal cracks and obvious decline of anti-sliding ability. Meanwhile, the pavement structure depth was unevenly distributed due to the separation of mixture in the early paving process, and the coefficient of variation of anti-sliding performance on the same section was large, which affected the comfort and safety of driving. In order to effectively improve the service performance of this section, and provide reference experience for the selection of appropriate maintenance measures for Guizhou Expressway in the future, after the traditional maintenance measures were adopted to repair the pavement cracks and other diseases in August 2020, the whole tunnel pavement was treated with epoxy surface maintenance technology.

\section{Construction scheme of the epoxy surface treatment technology}

The epoxy asphalt and fine aggregates were distributed to the original asphalt pavement through the special construction equipment, then a fine anti-sliding thin layer and epoxy surface layer could be formed. After rolling, traffic could be opened quickly. It had the functions of sealing micro cracks, repairing the aging structure of road surface, improving the waterproof and skid resistance of asphalt pavement, and improving the appearance of road surface. Generally, there were two kinds of treatment structure: single-layer and double-layer. According to the actual pavement technical conditions, road grade, traffic load and service performance requirements of the Guizhou Yilaga Tunnel, the double-layer structure has preferred in this construction. The double-layer epoxy surfacing treatment was divided into five layers. The main raw materials from bottom to top included epoxy asphalt, 2-4mm basalt aggregate, modified emulsified asphalt, 1-3mm basalt aggregate and also modified emulsified asphalt. The amount and proportion of each kind of material would directly affect the final construction quality of the epoxy surfacing. Through the method of medium value preset of material consumption, and combined the on site evaluation test, the optimum material consumption was designed, which has been shown in Table 1.

Table 1. The optimum material consumption of epoxy surface treatment for the Yilaga Tunnel.

\begin{tabular}{|c|c|c|c|c|c|}
\hline Materials & $\begin{array}{c}\text { Epoxy } \\
\text { asphlat }\end{array}$ & $\begin{array}{c}2-4 \mathrm{~mm} \\
\text { basalt } \\
\text { aggregate }\end{array}$ & $\begin{array}{c}\text { Modified } \\
\text { emulsified } \\
\text { asphalt }\end{array}$ & $\begin{array}{c}1-3 \mathrm{~mm} \\
\text { basalt } \\
\text { aggregate }\end{array}$ & $\begin{array}{c}\text { Modified } \\
\text { emulsified } \\
\text { asphalt }\end{array}$ \\
\hline $\begin{array}{c}\text { Material } \\
\text { consumption } \\
\left(\mathrm{kg} / \mathrm{m}^{2}\right)\end{array}$ & $0.35-0.45$ & $3.5-4.5$ & $0.25-0.45$ & $2.5-3.5$ & $0.2-0.4$ \\
\hline
\end{tabular}




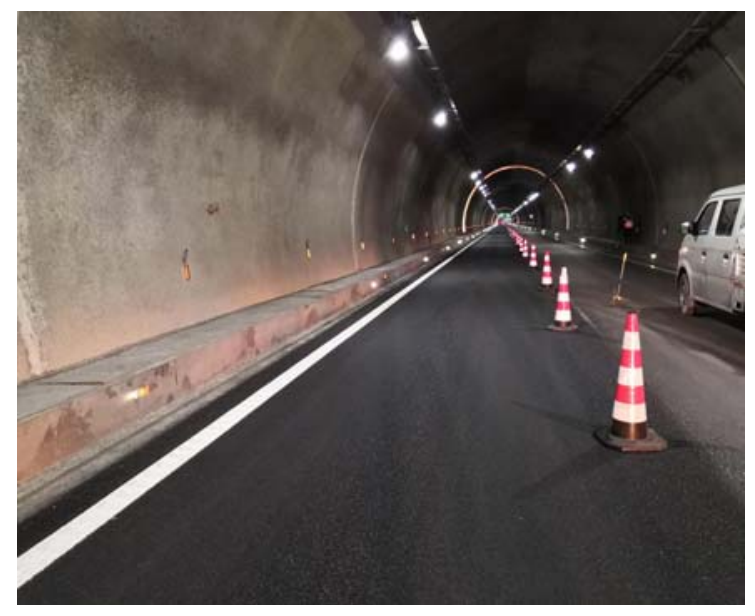

Fig. 1. Effect after construction completion.

\section{Detection and analysis of using effect of epoxy surface treatment}

According to the relevant requirements in the current specification 'Field Test Specification for Highway Subgrade and Pavement' (JTG 3450-2019), indexes including the appearance quality, tilting friction coefficient, structural depth, water permeability coefficient and bonding strength of the Yilaga Tunnel were observed before and after the construction of the epoxy surface treatment, to verify the application effect of the technology.

\subsection{Appearance quality}

The appearance quality has been observed, pictures are shown in Figure. 2 and Figure 3. It could be seen that after using the epoxy surface treatment technology on asphalt pavement, the appearance of the pavement was smooth and dense, the color was uniform and consistent, and there was no oil spilling and grain dropping. The overall appearance quality was satisfied after construction for three months.

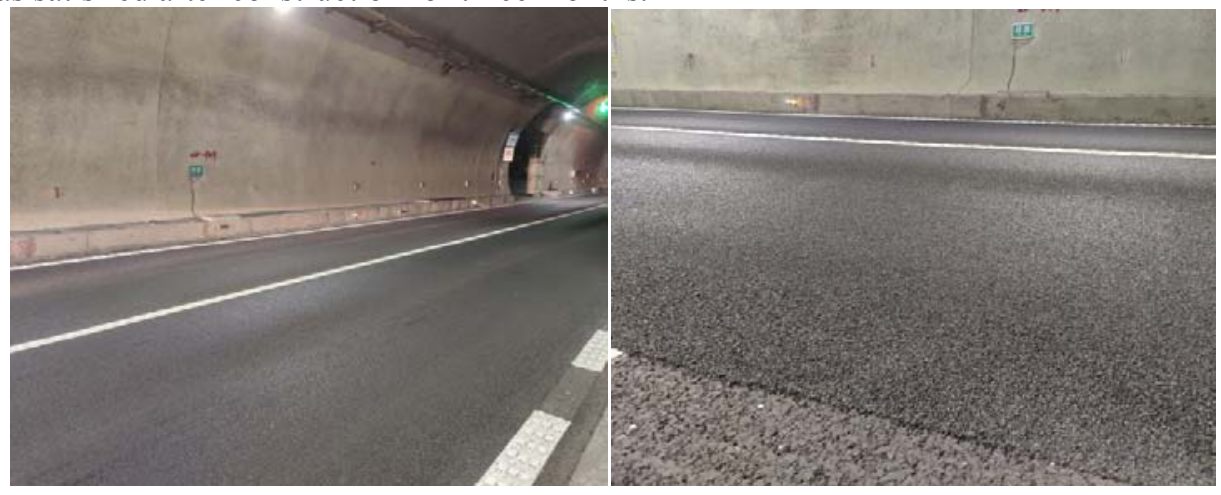

Fig. 2. Effect of one month after construction.

Fig. 3. Effect of three months after construction. 


\subsection{Friction coefficient of pendulum}

The pendulum friction coefficient instrument was used to test the friction coefficient of the epoxy surface pavement, at the frequency of 3 places (lanes $/ \mathrm{km}$ ). The test results are shown in Table 2. It can be seen that the overall anti-sliding performance of asphalt pavement with epoxy surface treatment technology has been significantly improved. It can still reach the high anti-sliding level of 77BPN after three months construction, so the anti-sliding performance was prominent.

Table 2. Friction coefficient test results before and after construction of the Yilaga Tunnel.

\begin{tabular}{|c|c|c|c|c|}
\hline \multirow{2}{*}{$\begin{array}{c}\text { Driving } \\
\text { direction }\end{array}$} & \multicolumn{4}{|c|}{ Mean value of pendulum friction coefficient (BPN) } \\
\cline { 2 - 5 } & Before construction & \multirow{2}{*}{$\begin{array}{c}\text { One month after } \\
\text { construction }\end{array}$} & Three month after construction \\
\cline { 4 - 5 } & & 79 & 77 & $60 \%$ \\
\hline Up & 48 & 78 & 77 & $48 \%$ \\
\hline Downward & 52 & Value & $\begin{array}{c}\text { Percentage of } \\
\text { improvement }\end{array}$ \\
\hline
\end{tabular}

\subsection{Texture depth}

The manual sand paver was used to test the structural depth of the epoxy surface pavement, at the frequency of 3 places (lanes $/ \mathrm{km}$ ). The test results are shown in Table 3, and it can be seen that the macro structure depth of asphalt pavement with epoxy surface treatment technology was greatly improved, and the distribution was uniform. Three months after construction, the macro structure of the road surface still maintained at a high level, which has provided enough anti-sliding interface and better guaranteed the driving safety of roads.

Table 3. Structural depth test results before and after construction of the Yilaga Tunnel.

\begin{tabular}{|c|c|c|c|c|}
\hline \multirow{2}{*}{$\begin{array}{c}\text { Driving } \\
\text { direction }\end{array}$} & \multicolumn{4}{|c|}{ Mean value of structural depth (mm) } \\
\cline { 2 - 5 } & $\begin{array}{c}\text { Before } \\
\text { construction }\end{array}$ & \multirow{2}{*}{$\begin{array}{c}\text { One month after } \\
\text { construction }\end{array}$} & \multicolumn{2}{|c|}{$\begin{array}{c}\text { Three month after } \\
\text { construction }\end{array}$} \\
\cline { 4 - 5 } & & 1.00 & Value & $\begin{array}{c}\text { Percentage of } \\
\text { improvement }\end{array}$ \\
\hline Up & 0.74 & 1.00 & 1.00 & $35 \%$ \\
\hline Downward & 0.70 & &
\end{tabular}

\subsection{Permeability coefficient}

The permeability coefficient of the epoxy surface pavement was tested at the frequency of 3 places (lanes $/ \mathrm{km}$ ). The test results are shown in Table 4 , and it can be seen that the permeability coefficient was 0 , and waterproof performance of the pavement was effectively improved.

Table 4. Test results of the permeability coefficient before and after construction.

\begin{tabular}{|c|c|c|c|}
\hline \multirow[b]{2}{*}{$\begin{array}{l}\text { Driving } \\
\text { direction }\end{array}$} & \multicolumn{3}{|c|}{ Detection mean value of permeability coefficient ( $\mathrm{ml} / \mathrm{min})$} \\
\hline & $\begin{array}{c}\text { Before } \\
\text { construction }\end{array}$ & $\begin{array}{l}\text { One month after } \\
\text { construction }\end{array}$ & $\begin{array}{l}\text { Three month after } \\
\text { construction }\end{array}$ \\
\hline Up & 103 & 0 & 0 \\
\hline Downward & 67 & 0 & 0 \\
\hline
\end{tabular}




\subsection{Bond strength}

The bond strength of asphalt pavement treated with epoxy surface treatment technology was tested by the pull-out tester at the frequency of 3 places (lanes $/ \mathrm{km})$. The test results are shown in Table 5, and it can be seen that the bonding strength between the epoxy surface treatment and the original pavement after three month of operation has reached more than 1.3 MPa, which has proved the excellent bonding ability and adhesion.

Table 5. Test results of bond strength before and after construction of the Yilaga Tunnel.

\begin{tabular}{|c|c|c|}
\hline \multirow{2}{*}{ Driving direction } & \multicolumn{2}{|c|}{ Mean value of bond strength test (MPa) } \\
\cline { 2 - 3 } & One month after construction & Three month after construction \\
\hline Up & 1.276 & 1.368 \\
\hline Downward & 1.205 & 1.412 \\
\hline
\end{tabular}

\section{Conclusion}

Based on the typical disease characteristics of the Yilaga Tunnel pavement in Guizhou, the epoxy surface treatment was used for improving pavement quality. Long term tracking and testing results showed that the epoxy surface treatment technology could effectively solve the original pavement diseases such as loose, pockmarked surface and dropping particles, and significantly improve the anti-sliding performance, safety performance, sealing and waterproof performance and durability of the pavement. It could be considered as a effective pavement maintenance technology, and it is worthy to applicate in Guizhou expressway.

\section{References}

1. M.M. Tian, X.Y. Wu, Y.F. Li and X.L. Chen, Application Research on Highway Surface Treatment of Epoxy Asphalt, 2021 6th International Conference on Green Materials and Environmental Engineering, 2021(2):203-208

2. Z. Li, L.X. Kong, G. Wang and G.Y. Su, Evaluation of Anti-sliding Decay Characteristics of Asphalt Pavement with Average Stress Gradient Highway Engineering 2018,43(5):33-36,41.

3. T. Song, Construction technology of anti sliding surface of Expressway Pavement, Transportation world, 2018,19:16-17

4. H.T. Sun, F.M. Zeng, Application of Micro Surfacing Technology in Expressway Maintenance Jiangxi Building Materials 2018(1): 139-141.

5. J. Chen, B. Peng and X.M. Huang, Investigation and Analysis on the Usage of Micro Surfacing Pavement Highway Transportation Technology 2007, 24(12):34-37.

6. X.L. Chen, X.Y. Wu and X. Hu, Application of Precision Surfacing in Anti-sliding Maintenance of Expressway Green Transportation 2019(2):203-204.

7. X.Y. Wu, H.M. Chen, Application of Asphalt Pavement Maintenance Agent in Urban Road Municipal Facilities Management 2011(2):26-27.

8. Ministry of Transport of China, Field Test Specification for Highway Subgrade and Pavement (JTG 3450-2019) 